\title{
Causation, complexity, and the concert: the pragmatics of causal explanation in international relations
}

Article

Accepted Version

Humphreys, A. R. C. (2017) Causation, complexity, and the concert: the pragmatics of causal explanation in international relations. Journal of International Relations and Development, 20 (4). pp. 717-736. ISSN 1581-1980 doi:

https://doi.org/10.1057/jird.2016.10 Available at https://centaur.reading.ac.uk/46877/

It is advisable to refer to the publisher's version if you intend to cite from the work. See Guidance on citing.

To link to this article DOI: http://dx.doi.org/10.1057/jird.2016.10

Publisher: Palgrave Macmillan

All outputs in CentAUR are protected by Intellectual Property Rights law, including copyright law. Copyright and IPR is retained by the creators or other copyright holders. Terms and conditions for use of this material are defined in the End User Agreement.

www.reading.ac.uk/centaur 
Central Archive at the University of Reading

Reading's research outputs online 


\title{
Causation, Complexity, and the Concert: The Pragmatics of Causal Explanation in International Relations
}

\begin{abstract}
A causal explanation provides information about the causal history of whatever is being explained. However, most causal histories extend back almost infinitely and can be described in almost infinite detail. Causal explanations therefore involve choices about which elements of causal histories to pick out. These choices are pragmatic: they reflect our explanatory interests. When adjudicating between competing causal explanations, we must therefore consider not only questions of epistemic adequacy (whether we have good grounds for identifying certain factors as causes) but also questions of pragmatic adequacy (whether the aspects of the causal history picked out are salient to our explanatory interests). Recognizing that causal explanations differ pragmatically as well as epistemically is crucial for identifying what is at stake in competing explanations of the relative peacefulness of the nineteenth-century Concert system. It is also crucial for understanding how explanations of past events can inform policy prescription.
\end{abstract}

\section{Keywords:}

Causation; causal explanation; pragmatism; IR theory; rationalism; Concert of Europe

In the study of world politics we are often confronted with competing causal explanations. How should we adjudicate between them? More specifically, how should we evaluate competing causal explanations which involve differing degrees of causal complexity? We might intuit that the fuller (more complex) explanation is more likely to be accurate. We might equally intuit that the simpler explanation better cuts through the noise to reveal what is really going on. ${ }^{1}$ We might go further and associate these intuitions with history and theory respectively, inferring that the choice between 
them is an aesthetic one. I contend that these sorts of intuitions are inadequate to the task. So, too, is the intuition that we should adjudicate between them purely on the basis of their consistency with the facts. In order to evaluate competing explanations, especially those involving differing degrees of complexity, we must consider the 'pragmatics' of causal explanation, that is, the extent to which individual explanations provide the causal information required by their audiences. ${ }^{2}$

The most familiar criterion of adequacy for a causal explanation is epistemic: we must have good theoretical and evidential grounds for identifying causal connections. Yet because such connections are continuous, extending back in time almost ad infinitum, and because descriptions of them can be made ever more fine-grained, we can never provide complete causal histories. Developing a causal explanation therefore requires us to choose which part of a causal history to include and how richly to describe it. Such choices are pragmatic: they are driven by the nature of our interest in our object of inquiry. ${ }^{3}$ The intrinsic role of these pragmatic choices in causal explanation implies that criteria of epistemic adequacy are necessary but insufficient for evaluating and comparing such explanations. Criteria of pragmatic adequacy are a necessary counterpart. ${ }^{4}$ We must provide good grounds for believing that factors identified as causes are indeed causally linked to our object of inquiry. We must also show that our prioritization among those factors responds adequately to our explanatory interests. ${ }^{5}$

In order to see the importance of examining how pragmatic choices shape causal explanations in IR, consider what appear to be competing explanations of the relative peacefulness of the nineteenthcentury Concert system. ${ }^{6}$ Rationalist theorists offer an artfully simple explanation. Slantchev (2005) argues that the territorial settlement established at the Vienna Congress generated a self-enforcing equilibrium: the incentive structure created was an individually sufficient cause of sustained great power peace. ${ }^{7}$ By contrast, many historians identify a much greater degree of causal complexity at work. For example, Schroeder (1992a: 694) argues that material incentives contributed to and were 
reinforced by an emergent 'political equilibrium' involving a 'mutual consensus on norms and rules, respect for law, and an overall balance among the various actors in terms of rights, security, status, claims, duties, and satisfactions'. This suggests that multiple causal factors were in play and that there were significant interaction effects among them.

One way of responding to the differences between these apparently competing causal explanations would be to note that Slantchev is a theorist and Schroeder a historian and to infer that we simply face an aesthetic choice between competing disciplinary approaches. ${ }^{8}$ Yet this is unsatisfactory, for causal explanations can surely be evaluated on more than aesthetic grounds. A second, more promising, response is to treat these explanations as differing epistemically, that is, as making competing claims about what the facts show. This suggests that we need to assess the adequacy of the evidence that each provides for identifying particular factors as being causally linked to our object of explanation. This is probably the most common (and also intuitive) approach to evaluating causal explanations in IR. However, treating the debate between Slantchev and Schroeder as purely epistemic requires us to construe Slantchev's argument in an implausible fashion, for Slantchev is surely not arguing that the incentive structure is literally the only factor that is causally linked to the relative peacefulness of the Concert system (after all, that incentive structure has its own causal history).

In fact, like any causal explanation, Slantchev's approach is strongly shaped by pragmatic choices. Rather than arguing that the incentive structure is the only cause in play, Slantchev is more plausibly interpreted as arguing that if we cut into the causal history of the Concert system in 1815 then it is the only factor we need to examine to explain the system's subsequent peacefulness. This claim is a pragmatic one: that we only need to examine one segment of the causal history and that even this segment need be examined only under a particular description. It begs the question: in responding to what explanatory interests do we only need to focus on this part of the causal history? I will 
argue that if we are principally interested in how it came about historically that the Concert system was relatively peaceful, we are unlikely to find this kind of simplification pragmatically adequate. If that is our interest, we are likely to find Schroeder's explanation pragmatically superior. In fact, we are only likely to be satisfied with the rationalist approach if, as many IR theorists do (see Ikenberry 2001; Kupchan 2012), we approach the period from the perspective of the present, asking which of the (perhaps many) causal factors that contributed to the system's peacefulness are most relevant to an attempt to secure great power peace today.

There is therefore an important sense in which Slantchev and Schroeder talk past one another. ${ }^{9}$ For all that Slantchev claims to improve on Schroeder by providing a better historical explanation, he is best understood as pursuing a different goal, viz. to demonstrate that, as rationalist theory would predict, the incentive structure was an important cause of the system's peacefulness. This goal has both intrinsic and instrumental value. Its intrinsic value is that it promises to tell us something useful about the Concert system. Its instrumental value is that if the incentive structure was indeed an important cause (which few, including Schroeder, contest), then this seems to buttress the claim of rationalism, in virtue of its focus on such incentive structures, to prescribe how great power peace might be produced in the future. Yet this means that the way in which the rationalist approach is presented is somewhat misleading, for what appears like an explanation to directly rival Schroeder's is no such thing. This is, in fact, quite common in IR: theorists frequently present partial explorations of key historical episodes, viewed from the perspective of the present, as if they were adequate explanations of why those episodes happened as they did. When the ability to explain such episodes is then proposed as a reason to follow policy prescriptions derived from those theories, evaluation of the conditions of pragmatic adequacy attaching to such explanations is strongly called for.

This exploration of debates about the peacefulness of the Concert system illustrates how in order to evaluate causal explanations we must pay close attention to the pragmatic choices they embody and 
the explanatory interests they serve. Yet despite renewed interest in causation in world politics (see Kurki 2008) this aspect of causal explanation is rarely discussed. This paper therefore has three goals. First, it provides a framework for scrutinizing the intrinsic role of pragmatic choices in causal explanations. Second, it illustrates how deeply pragmatic choices can shape causal explanation in IR by revealing the conditions of pragmatic adequacy which attach to competing explanations of the peacefulness of the Concert system. It also thereby clarifies what some of these debates about the nineteenth-century Concert system are really about. ${ }^{10}$ Finally, it suggests that focusing on the pragmatics of causal explanation is as important for policy debates as for theoretical and historical debates. Given that theorists often seek to demonstrate their theories' credentials by showing how they can explain crucial historical episodes, it is essential to ask when theoretical simplification of the kind that rationalists employ in relation to the Concert system is pragmatically justified.

\section{The Pragmatics of Causal Explanation}

There is no firm consensus among philosophers about what constitutes a causal explanation, let alone an adequate one. There has, nonetheless, been a decisive move away from the covering-law model, according to which we explain an event by subsuming it under a general law stipulating the conditions sufficient for the occurrence of such events. The covering-law model implies that singular causal explanations (that is, explanations of specific events) are truncated versions of more general explanations: the statement "the short-circuit caused the fire" is explanatory only insofar as it is understood as implying a general law to the effect that, under specifiable conditions, short circuits always produce fires. One problem with this model is that we often construct causal explanations which cannot be generalized in this way and that they prove comprehensible even to those unaware of what, according to the covering-law model, is supposed to make explanations explanatory (viz. their empirical generalizability). ${ }^{11}$ Woodward (1993: 249) therefore argues that the covering-law 
model fails to identify the features of singular causal explanations 'which function so as to produce understanding in the ordinary user'.

This criticism points towards an intuitive account of an explanation as something which produces (or confirms) understanding in its audience. ${ }^{12}$ According to Lewis (1993: 185) a causal explanation does this by providing information about the causal history of our object of explanation. ${ }^{13}$ However, this creates what philosophers term a problem of causal selection, for as Lewis (1993: 182) notes:

Any particular event that we might wish to explain stands at the end of a long and complicated causal history. We might imagine a world where causal histories are short and simple; but in the world as we know it, the only question is whether they are infinite or merely enormous ... Further, causal chains are dense ... A causal chain may go back as far as it can go and still not be complete, since it may leave out intermediate links.

If, as Lewis argues, we cannot give a complete causal history, then causal explanations must select only some elements of causal histories. Yet as Lewis (1993: 183) notes: '[t]here is no one right way ... of carving up a causal history'. Thus when we claim to have identified 'the cause of something' we are really making a claim about 'which part of the causal history is most salient for the purposes of some particular inquiry'. In other words, causal explanations involve choices about which aspects of an event's causal history to include. Such choices are pragmatic: they are shaped by the interests which motivate our inquiry.

To see how this aspect of causal explanation is distinct from the epistemic aspect on which attention usually focuses, consider Lewis's (1993: 182-4) example of a car crash featuring an icy road, a bald tire, a drunk driver, a blind corner, and an approaching car. Focusing on the epistemic aspect of causal explanation, we will examine the evidence for regarding these factors as being causally linked to the crash. Let us suppose we have good counterfactual reasons for supposing that without any one of these conditions the accident would not have happened. ${ }^{14}$ Which is the cause? All of them, 
perhaps? If so, then what of the causes of these causes? And, to extend Lewis's example, what of the failure to grit the road, or the negligent mechanic? Moreover, what level of detail is required? How bald was the tire and which side of the road was the approaching car on? Sometimes, it is clear which causes are relevant. In court, the driver, in virtue of having been drunk, may be found responsible for the accident. But if we are interested less in questions of agential responsibility and more in how future such accidents can be avoided, we might focus more centrally on the signage. The point is not that anything goes, but rather that in addition to being epistemically adequate a causal explanation has to achieve closeness of fit with the interest that motivates the inquiry. This, in turn, requires clarity about the nature of our explanatory purpose, that is, about what question is really being asked. To illuminate this, I now turn to van Fraassen's work on the pragmatics of causal explanation. ${ }^{15}$

According to Van Fraassen (1980: 123-4), 'science gives us a picture of the world as a net of interconnected events, related to each other in a complex but orderly way'. Causal explanations draw on this picture in the following way:

1. Events are enmeshed in a net of causal relations

2. What science describes is that causal net

3. Explanation of why an event happens consists (typically) in an exhibition of salient factors in the part of the causal net formed by the lines "leading up to" that event

4. Those salient factors mentioned in an explanation constitute (what are ordinarily called) the cause(s) of that event.

Thus an explanation is epistemically adequate if the causes it picks out are identified scientifically as part of the causal net in which the event we are explaining is enmeshed ( 1 and 2 , above), but it is only pragmatically adequate if those causes are salient to the interests which motivated the search for an explanation ( 3 and 4, above). As van Fraassen (1980: 126) puts it: 'no factor is explanatorily 
relevant unless it is scientifically relevant; and among the scientifically relevant factors context determines explanatorily relevant ones'.

Van Fraassen's analysis of contextual (or pragmatic) salience is developed through his theory of whyquestions. He argues (1980: 134) that an explanation 'is an answer ... to a why-question', an answer which combines scientific and contextual factors. The scientific content is provided by the theory on which the explanation draws: what makes an answer to a why-question a scientific explanation is that science is used to identify the set of causes from which the most salient ones must be chosen. Contextual factors come in because the precise information requested in the question "Why is it the case that $P$ ?", differs from context to context' (van Fraassen 1980: 155-6). What van Fraassen (1980: 143) terms the 'topic' of the question determines which scientific theories are applied in order to identify the causal history, but which elements of that causal history are salient will depend on what precisely the question is interpreted as asking. Identifying an explanation as an answer to a whyquestion therefore highlights the unavoidable pragmatic component of causal explanation. ${ }^{16}$

Van Fraassen identifies two ways in which why-questions can be clarified, thus clarifying in turn what causal information is pragmatically salient. The first involves recognizing that the underlying structure of a why-question involves an implicit contrast class, $X$ : the question is never really 'Why (is it the case that) $P$ ?', but rather 'Why (is it the case that) $P$ in contrast to (other members of) $X$ ?' (van Fraassen 1980: 127). In other words, even when we are asked 'Why $P$ ?' we are not really being asked to provide $P^{\prime}$ 's complete causal history (which would be impossible), but are instead being asked to explain why $P$ rather than another possible outcome (call it $Q$ ). This may not immediately be obvious, because the contrast is often implicit, but van Fraassen's argument (1980: 128) is that making it explicit helps to clarify what information is salient: we need to 'adduce information that favours $P$ in contrast to other members of $X^{\prime}$, that is, information which is relevant to why $P$ happened rather than $Q$. 
The idea that explanation is contrastive is widely accepted. ${ }^{17}$ However, van Fraassen argues that the pragmatic aspect of explanation runs deeper than other proponents of a contrastive approach allow. For example, Woodward (1993: 267) argues that when we have specified the relevant contrast it becomes an entirely objective matter what needs to be included in a causal explanation. In other words, he contends that the contrastive approach dissolves problems of causal selection. Yet if we take seriously Lewis's claim that causal histories are both extensive and dense, then it is not obvious why this might be. Specifying a contrast class is a means of helping us to make salient choices, not a step which obviates the need to make such choices: the question of salience still arises. Hence for van Fraassen (1980: 130) there is a second way in which why-questions can be clarified. He argues that they are not only contrastive, but also involve a 'relevance relation': even when we recognize that we are trying to explain why ' $P$ rather than $Q$ ', we still have to pick out which aspect of ' $P$ rather than $Q^{\prime}$ is relevant to particular explanatory interests.

Van Fraassen (1980: 141-2) gives an example of how these two steps work together in relation to the question 'Why is this conductor warped?' First, we note that multiple contrast classes are available. Thus the question might be understood as a request for information about why this conductor is warped (rather than that one) or about why this conductor is warped (rather than retaining its shape). Second, we must consider what it is the inquirer seeks to understand. For example, the request might be for events "leading up to" the warping. That allows as relevant an account of human error, of switches being closed or moisture condensing in those switches ... On the other hand, the events leading up to the warping might be well known, in which case the request is likely to be for the standing conditions that made it possible for those events to lead to this warping: the presence of a magnetic field of a certain strength, say. Finally, it might already be known, or considered immaterial, exactly how the warping is 
produced, and the question (possibly based on a misunderstanding) may be about exactly what function this warping fulfils in the operation of the power station.

In other words, even once the contrast class is clarified, a causal explanation may still be more or less pragmatically adequate.

There is one remaining ambiguity about how deeply the influence of pragmatic factors on causal explanation runs. Kitcher and Salmon (1993: 313) interpret van Fraassen as arguing that once we have specified the contrast class and relevance relation we have fully captured the pragmatic aspect of causal explanation and can henceforth focus entirely on questions of epistemic adequacy. ${ }^{18}$ This interpretation is apparently supported by van Fraassen's suggestion (1980: 129) that 'listing salient factors' points to 'a complete story of how the event happened'. However, van Fraassen (1980: 124) asserts that 'to describe the whole causal net in any connected region, however small, is in almost every case impossible'. Thus even if we have determined that an answer to the question 'Why is this conductor warped?' must consist in an account of 'events leading up to the warping', giving such an account will involve further choices about causal selection, for the entire history of events leading up to the warping cannot be related. This suggests that relevance relations are irreducibly pragmatic: what counts as relevant cannot be determined algorithmically, but will always be subject in part to the judgement of the explanation's recipient. ${ }^{19}$ A good explanation is one that, from the perspective of its audience, is both epistemically acceptable and also achieves a sufficiently close fit between the pragmatic choices it embodies and the interests that motivated the inquiry.

Two key points emerge from this discussion. First, causal explanations have an irreducibly pragmatic component: by definition, causal explanations involve choices about causal selection. Evaluation of causal explanations therefore cannot focus exclusively on epistemic adequacy, that is, on the quality of the evidence and reasoning offered for identifying particular factors as being causally linked to the object of explanation. In many cases, competing causal explanations will not differ merely (and may 
not differ at all) over the facts. Indeed, differences which we may intuitively suppose to be about the facts often turn out to concern questions of emphasis which are pragmatic, not epistemic, in nature (see Martin 1982: 59).

Second, and consequently, evaluation of competing causal explanations must pay attention to their conditions of pragmatic adequacy. This is not to say that any explanation is as good as any other. Rather, it is to identify that a good explanation is one which, in addition to satisfying criteria of epistemic adequacy, achieves closeness of fit between its choices about causal selection and the explanatory interests to which it responds. This entails, inter alia, that a causal explanation involving a greater degree of causal complexity is not necessarily either better or worse than one involving a lesser degree: the degree of complexity that is appropriate will depend on our explanatory purpose. That said, we can and should ask of a putative explanation: to what interests does this adequately respond? With this in mind, I now turn to debates about what caused the relative peacefulness of the nineteenth-century Concert system.

\section{Causal Complexity and the Concert System}

Competing explanations of the relative peacefulness of the Concert system offer a revealing insight into how pragmatic choices shape causal explanations. Several characteristics make this a useful case to consider. First, given IR's practical concern with mitigating the risks of war, we need to be able to adjudicate between competing explanations of how that has been achieved in the past. Second, a wide range of approaches have been adopted in pursuit of the same goal, viz. explaining the system's relative peacefulness. Third, the influence of pragmatic concerns on these approaches is quite explicit: theorists, in particular, tend to be interested in the Concert system because they hope to replicate its successes. ${ }^{20}$ In what follows, I focus on two approaches: that initially developed by Jervis $(1982,1985,1992)$ and further elaborated by Slantchev (2005) and that articulated by 
Schroeder $(1986,1989,1992 a, 1996)$. I focus on these not because I take them to be representative of theory and history in IR (or rationalism and constructivism), but rather because Jervis (1992) and Slantchev (2005) explicitly compare their approach to Schroeder's (see also Schroeder 1992b) and because the contrast between them illustrates the role of pragmatic considerations rather clearly. ${ }^{21}$ My aim is twofold: first, to show that differences which may appear, on the surface, to be epistemic (about the facts and how they should be interpreted) are in fact pragmatic; and second, to show that the kind of simplification employed in rationalist approaches is pragmatically adequate only if we have a very particular explanatory interest in mind.

Although there is no accepted definition of causal complexity, various kinds may be distinguished, including: (i) multi-causality (the presence of multiple causes); (ii) the absence of necessary and sufficient conditions; (iii) equifinality (multiple causal pathways to a particular outcome), including overdetermination (multiple independently sufficient causes of an outcome); (iv) the presence of probabilistic causal mechanisms; and ( $v$ ) a variety of interaction effects and forms of nonlinearity, including path dependency, multifinality (multiple outcomes consistent with the same value of a causal variable), tipping points, emergent properties, feedback effects, endogeneity between agents and structures, and the responsiveness of agents to social theories. Given that world politics is a social realm inhabited by human agents acting within multiply overlapping contexts, and that states are multifaceted ensembles of such agents, it seems reasonable to suppose that all these forms of complexity are present. Moreover, given that great power peace has not, historically, proved easy to sustain, one might expect at least some of them to be features of the Concert system. Rationalist explanations of its relative peacefulness, however, incorporate none of them. ${ }^{22}$

The rationalist approach proceeds against a key background assumption: the Concert system was an exception to the norm of balance of power politics (Jervis 1985: 59). Great powers are identified as rational, self-interested actors competing under anarchy and the puzzle is why the Concert system 
produced more cooperative behaviour than would be expected (Slantchev 2005: 569; Jervis 1992: 717). Rationalists locate the solution in just two causal factors: interests and incentives. Jervis (1985: 60) describes how the experience of hegemonic war changed the perceived payoffs of great power competition: until about 1823 , fear of renewed war caused the great powers to cooperate out of self-interest. When this transitory confluence of interests subsided, the incentives created by the post-war settlement sustained peace for another quarter-century (Jervis 1982: 365-6). Slantchev (2005: 566) pushes this approach even further by focusing exclusively on the incentive structure: he argues that the end of a hegemonic war created an opportunity for the great powers to establish a new territorial settlement. Because each of the great powers accrued benefits proportional to its military power (Slantchev 2005: 590) and knew that attempts to expand further would be opposed, this settlement created self-enforcing incentives against revisionism. It thereby maintained great power peace until the system was disrupted by revolution in 1848 and by external pressures, in the shape of the Crimean War, in 1853/4.

Hence whatever the appearance of causal complexity, the rationalist claim is that an adequate explanation of the relative peacefulness of the Concert system can be developed by focusing only on great powers' interests and the incentive structure they faced. Indeed, Slantchev (2005: 567-9) argues that the changed incentive structure was not only sufficient to produce stable peace among rational self-interested actors, but was the only way in which it could have been produced. In other words, a territorial settlement generating a self-enforcing equilibrium was an individually necessary and sufficient cause of the peacefulness of the Concert system.

Schroeder (1986: 2) concurs with Jervis and Slantchev that the difference between eighteenth- and nineteenth-century great power politics was structural and not just dispositional. Yet he envisages structural change as going altogether deeper than a change in the incentive structure. He identifies three 'constitutive elements' of the Concert system: 'the treaty system of 1815 and the European 
Concert; the "fencing off" of the European state system from the extra-European world; and the establishment of a system of intermediary bodies between the great powers' (Schroeder 1986: 12). On one level, each of these elements is related to the territorial settlement. Yet whereas Slantchev (2005: 572) regards the restriction of that settlement to Europe as a weakness that partly accounts for the collapse of the Concert system in 1853/4, Schroeder (1986: 16) emphasizes the mutually constitutive relationship between peace in Europe and the great powers' changed attitudes to extraEuropean conflict. Whereas Slantchev (2005: 583-5) regards the territorial settlement as stable because it ignored the rights of lesser states, Schroeder (1986: 17, 12) argues that intermediary bodies provided common management problems for the great powers and stresses that the postwar settlement recognized the legitimacy of all states' interests.

Schroeder therefore emphasizes how the legitimacy of the territorial settlement fed back into the great powers' commitment to upholding it. This exemplifies the greater causal complexity involved in his explanation. Like Slantchev, Schroeder (1986: 12) emphasizes that the great powers 'worked out Europe's boundaries in a way mutually tolerable to all the important powers ... and then guaranteed these territorial arrangements by a series of interlocking treaties and a general greatpower alliance'. However, rather than treating this territorial settlement as an individually sufficient cause of great power peace, he notes that it was reinforced by 'a system of diplomacy by conference and some general principles of a European Concert'. It is these principles of European concertation which are, ironically, absent from rationalist explanations of the peacefulness of the Concert system.

According to Schroeder (1972: 405), the principles of the Concert included: (i) the right of the great powers to decide 'great European questions', (ii) an injunction against war for 'territorial gain' and the promotion of 'revolution or unrest within another great power's territory or sphere of vital interest', (iii) an injunction against raising questions 'of vital interest to a great power ... without its consent', (iv) an obligation to participate in a conference should 'a problem of genuine international 
import' arise, and $(\mathrm{v})$ the avoidance at all cost of 'direct challenges and confrontations between individual great powers', mainly by referring quarrels 'to the decision of the Concert'. These principles were not just a corollary of the territorial settlement, but grew out of the final coalition against Napoleon (Schroeder 1986: 12-13; see also Mitzen 2013: 85-6) and were explicitly intended to produce a political (and not just a territorial) equilibrium (Schroeder 1992b: 733). In other words, the territorial settlement was legitimated by its place within a broader political settlement: the Concert system was peaceful because structural incentives combined, in mutually reinforcing ways, with new political thinking. ${ }^{23}$ Although states continued to act self-interestedly, they did so in the context of a 'fundamental change ... in the governing rules, norms, and practices of international politics' (Schroeder 1996: v; see also Schulz 2007; Cohrs 2003: 12-13). Schroeder's explanation is therefore inconsistent with the idea that the incentive structure was an individually sufficient cause of great power peace. His account involves significant interaction effects among multiple causes.

In comparing these explanations, the first question to consider is whether the differences between them are epistemic or pragmatic. For them to be epistemic, there would have to be disagreement about the identification of causes. Given the notable absence of causal complexity in the rationalist approach, Jervis and Slantchev would have to be arguing that what Schroeder identifies as causal complexity only appears to be causal complexity: Schroeder mistakenly identifies as causes factors which are really epiphenomenal. A comparative evaluation would then have to assess the reasoning and evidence supporting the competing claims about whether certain factors are or are not causes. There is some evidence of this kind of disagreement. For example, Slantchev (2005: 579) rejects as 'an unwarranted assumption' the idea (which he attributes to Schroeder) that preferences were transformed: he doubts that persuasive evidence for such a change can be found. ${ }^{24}$ This suggests that Slantchev believes Schroeder to have mistakenly identified preference change as a cause of the relative peacefulness of the Concert system. 
Yet the differences between these explanations cannot be wholly epistemic. Recall that there are two aspects to causal explanation: identifying the elements of a causal history and identifying those which are most salient to particular explanatory interests. Slantchev's identification of the territorial settlement as an individually sufficient condition of the peacefulness of the Concert system is surely not meant to imply that this one factor constitutes the sum total of its causal history. His claim is surely that if we cut into the causal chain at the Treaty of Vienna, then from that point on it is sufficient merely to examine the incentive structure it produced. Schroeder's approach is very different: he explores the emergence (especially during the final coalition against Napoleon) of the new thinking which, in his account, created the conditions for a stable territorial settlement (see Schroeder 1989: 142; 1996: v-vi). For Schroeder, therefore, an adequate explanation does not start with the Vienna settlement, but identifies the factors which contributed to it. Hence whether or not they agree on the elements that make up the causal chain, Slantchev and Schroeder certainly cut into it at different points.

There are deeper reasons, too, for believing that the differences between the two explanations are at least partly pragmatic. Although he criticizes Schroeder for failing to provide adequate evidence of preference change, Slantchev (2005: 579) does not himself offer evidence that preferences were unchanged: instead, he assumes that they were unchanged, arguing that this assumption is justified on grounds of parsimony. This is surely a pragmatic claim about how complex an explanation needs to be, rather than an epistemic claim about the number of causal factors in play. Moreover, Jervis (1992: 716-7) notes explicitly that 'scholars differ in their aesthetic sense of the attractiveness of parsimony and richness'. Because they value parsimony, he argues, 'political scientists construct abstract models and theories', making the 'most obvious question' about the Concert system 'how international politics can maintain restraint and stability despite its being anarchic'. In short, the rationalist approach is explicitly shaped by a desire to simplify. It involves strong pragmatic choices 
not only about where to cut into the causal chain but also, having cut into it at a certain point, about the degree of detail in which it needs to be described.

If it is clear that at least some of the differences between these explanations are pragmatic, merely identifying this fact does not yet help us to evaluate them better. Indeed, it might seem to confuse things: whereas we can evaluate epistemic differences by reference to theory and evidence, once we allow that the differences partly pragmatic, this seems to imply that the two explanations are talking past one another and hence cannot be productively compared. This is where van Fraassen's framework proves its value, for it helps to identify the different interests to which the explanations constitute pragmatically adequate responses.

Parsing Schroeder's approach through the lens provided by van Fraassen's framework confirms that his topic is the relative peacefulness of the Concert system. His contrast class is other periods of similar duration in modern international relations: he seeks to explain, in particular, why great power politics was more peaceful in the nineteenth century than in the eighteenth. Indeed, he starts his survey in 1763 precisely in order to highlight this difference (see Schroeder 1996: xi). His relevance relation reflects his interest in high politics and diplomacy rather than, for example, longterm economic and social change (see Gruner 1992: 728). His aim is to show that statesmen can bring about systemic transformation through mutual accommodation (see Schroeder 1986: 26; 1996: xi). In effect, he answers the question: 'focusing on diplomacy and high politics and looking back as far as the mid-eighteenth-century, what caused the relative peacefulness of the Concert system as compared to other similar periods?' If we accept these parameters and the level of detail he provides, we are likely to accept his explanation as a pragmatically adequate account of how it came about historically that the Concert system was relatively peaceful. ${ }^{25}$ 
Parsing the rationalist approach through the lens provided by van Fraassen's framework generates a very different picture. As for Schroeder, the topic is the relative peacefulness of the Concert system: that is why they are comparable. But the contrast class, rather than being historical, is theoretical: the question is why peaceful relations endured rather than the great powers slipping back into the kind of conflictual balance of power politics which rationalists expect under anarchy. The relevance relation is then defined by the search for causal factors which are necessary for peace and would, in a simplified possible world constituted by rational actors, also be sufficient (see Slantchev 2005: 5679). The aim, in other words, is to pick out of the historical contingency of the Concert system those factors which would produce peace under similar but simplified conditions. In effect, the rationalists answer a hypothetical rather than a historical question, viz. 'which of the factors that contributed to the relative peacefulness of the Concert system would be sufficient to produce peace in a simplified world of rational actors?'

Interpreting the rationalist approach in this way helps to make sense of Slantchev's assertion that the incentive structure which emerged out of the Vienna settlement is the only thing that could explain sustained great power peace: in the simplified world depicted in his theoretical model, this is true. It also receives indirect support from Jervis's discussion of how, in practice, factors other than interests and incentives contributed to the system's peacefulness. Jervis (1985: 60) begins with a theoretical claim that concerts arise only after hegemonic wars because only that kind of disruption to normal balance of power politics can increase 'the incentives to cooperate'. Yet he then goes on to acknowledge that in the nineteenth-century Concert system the changed incentives created by the Napoleonic wars were reinforced by other factors, including the legitimacy which flowed from the use of ambassador conferences (Jervis 1985: 72). This seems to confirm that, for Jervis at least, the rationalist focus on interests and incentives is just that: a focus. His theoretical model is but a starting point in exploring a system characterized not only by multi-causality, but also by interaction effects and perhaps causal over-determination. ${ }^{26}$ 
Even if the rationalist approach is oriented toward answering a hypothetical rather than a historical question, answering this hypothetical question may be valuable, especially if we are interested in the Concert primarily for its implications for the present. But it should also be clear that if, instead, we are interested in how it came about historically that the system was peaceful, then the rationalist approach is inadequate, for why, in that case, would we be satisfied with an explanation that focuses exclusively on the incentive structure? Because all causal histories are both extensive and dense, no explanation can do everything. Yet if our interest is historical, will we not also want to know how the territorial settlement came about (Schroeder 1996) and how it interacted with new institutional structures and norms (Schulz 2007), with the development of collective intentions and public reason (Mitzen 2013), perhaps even with industrialization, rational state-building and ideologies of progress (Buzan and Lawson 2013)? The unavoidable conclusion is that construed as a historical explanation the rationalist approach is either epistemically or pragmatically inadequate. If it really claims that the incentive structure is the only cause in play, then it is not supported by the evidence. If it really claims that we only need to examine the incentive structure, then it is over-simplified.

I contend, therefore, that the rationalist account of the Concert system is best interpreted not as a historical explanation that directly rivals Schroeder's, but rather as an illustration of a theoretical claim. As Jervis notes, theorists tend to simplify by applying theoretical models and the rationalist approach to the Concert revolves around an analysis of the incentives present in a simplified world constituted solely by rational actors. Slantchev's insight is that in such a world a distribution of resources that produced self-enforcing incentives against revisionism would be in equilibrium and hence generate sustained peace. To the extent that the Concert system approximates this model, we might expect this dynamic to be present. And what Slantchev does in his historical discussion is to try to show that in some significant respects the system did approximate his model. Yet even if we grant that he succeeds in this, we still do not have a historical explanation to rival Schroeder's. 
The rationalist model may contribute to our historical investigations by giving us reason to suppose that the territorial settlement is causally significant, but an adequate historical explanation cannot end there.

Three key points emerge from this discussion. First, causal explanations are significantly shaped by pragmatic choices and our evaluation of them must reflect this. Second, debates about the Concert may not be about what they appear to be about. On first inspection, it appears that Schroeder and Slantchev are both trying to explain how it came about that the Concert system was peaceful. If we accept this, then we may also accept Jervis's contention that the differing degrees of complexity found in theorists' and historians' explanations simply reflects their differing aesthetic preferences. Yet when we examine the pragmatic choices made by Slantchev and Schroeder, it becomes apparent that their explanations are adequate to quite different explanatory interests. Whereas Schroeder's approach responds to an interest in how it came about historically that the Concert system was peaceful, Slantchev's responds to an interest in the conditions of peace in a similar but simplified world. Third, it is important how explanations are presented. Our ability accurately to discern how these explanations differ is impeded by the tendency of rationalists to present their approach as if it were, pragmatically speaking, directly rival to Schroeder's. In fact, it would be better described as an inquiry into what would produce peace in a simplified version of the Concert system. The problem with presenting it as an explanation of the peacefulness of the actual Concert system is that it does not offer the kind of explanation that most people interested in that topic will be looking for.

\section{Conclusion}

Although the idea is unfamiliar in IR, van Fraassen's framework shows how two causal explanations may share a topic and yet diverge significantly in the explanatory interests to which they constitute adequate responses. When comparing explanations, especially those involving differing degrees of 
causal complexity, it is therefore essential to consider whether their disagreements are epistemic or pragmatic, that is, whether they concern the identification of causes or their salience. This is not to downplay the significance of epistemic disagreements, but rather to situate them. If an explanation is pragmatically adequate in relation to some explanatory interest, this does not imply that it is also epistemically adequate: it may provide just the kind or degree of causal information we are looking for yet lack adequate theoretical and evidential justification for identifying particular factors as causes. Yet unless assessments of epistemic adequacy proceed within clear pragmatic parameters, we are liable to mistake pragmatic for epistemic differences: we cannot assess consistency with the facts until we know which facts are relevant. If an explanation focuses on a particular part of the causal chain, and hence ignores certain factors which different pragmatic choices would have highlighted, then this does not imply that the causal structure of the world has been misidentified: rather, it reflects (unavoidable) choices about causal selection.

Taking the pragmatics of causal explanation seriously may appear to expand the range of adequate explanations so far as to make evaluation difficult. This is not the case. The wide range of interests to which an explanation may respond implies that explanations may take many different forms, but we can and should remain demanding about what qualifies, pragmatically and epistemically, as an adequate explanation. To question whether the rationalist approach is pragmatically adequate as an explanation of how it came about historically that the Concert system was peaceful is not to soften our standards, but rather to impose an additional requirement over and above the more familiar emphasis on epistemic adequacy. A focus on the pragmatics of causal explanation also highlights some of the limitations of attempts to identify generic characteristics of history and theory and to generalize about how they differ (see Keene 2008; Lawson 2010). Jervis (1992: 716) may be right that theorists, unlike historians, tend to believe 'that one or two causes are primary in each case, and ... that the same factors are at work in numerous instances', but if so, are such beliefs epistemic (about the causal constitution of world politics) or pragmatic (about what sorts of explanations are 
most satisfactory)? In evaluating causal explanations, there is no substitute for close attention to the specific characteristics of each individual explanation, whatever its methodological roots.

Taking the pragmatics of causal explanation seriously also provides a useful perspective on claims that the ability of a theory to explain some historical episode provides a reason to follow its policy prescriptions. Many IR theorists not only seek to explain the peacefulness of the Concert system, but also use those explanations to buttress their theories' policy credentials. For example, Kupchan and Kupchan (1991: 129) present a 'deductive case ... that balancing under collective security more effectively deters and stops aggression than balancing under anarchy' and argue that this theory of collective security can explain the peacefulness of the nineteenth-century Concert system. They also claim that the 'underlying features of the nineteenth-century international system that gave rise to the Concert of Europe are once again present' and propose, on this basis, that a new 'concert-based collective security organization' should be created in Europe (Kupchan and Kupchan, 1991: 116; see also Rosecrance 1992; Slantchev 2005: 604-6). The logic of their position appears to be as follows: (i) their theory can adequately explain why the Concert system was peaceful; (ii) relevantly similar conditions obtain today; hence (iii) if the prescriptions of their theory are followed, the peacefulness of the Concert system can be reproduced today. Much therefore rests on whether their theory does indeed generate a pragmatically adequate explanation of the system's peacefulness. ${ }^{27}$

Most theory involves simplification: it explores the dynamics of simplified possible worlds. The reason for exploring these hypothetical scenarios is the hope that we can transfer our understanding from the simplified situation to a more complex reality. The extent to which we can do so depends on the extent to which reality approximates the model. The scenario we have explored in relation to rationalist explanations of the peacefulness of the Concert system is, in this respect, quite typical. Because the historical episode does not match the model precisely, the value of the model lies in its ability to indicate some of the dynamics likely to be in play. Yet if we wish to understand why things 
happened as they did, any explanation generated exclusively from the model is likely, in virtue of the simplification involved, to be pragmatically inadequate. We should therefore be cautious about accepting claims, such as that made by Kupchan and Kupchan, that because a theory can explain a particular historical episode it can also predict what might play out were similar dynamics to be put in train today. ${ }^{28}$ For if the theory really explains not what did happen, but rather what would have happened in a simplified possible world, then the same is true of its predictions: the theory does not tell us what will happen if we follow its policy prescriptions, but rather what would happen were we to follow those prescriptions in a simplified possible world.

This is not to denigrate theory. Insight into what would happen in a simplified possible world might well be highly relevant to our attempts to shape the future. But if so then we should be concerned not with the similarities between today's conditions and some historical episode, but rather with the similarities between today's conditions and the hypothetical conditions of our theoretical models. This is too often obscured by the claims theorists make about their ability to explain key historical episodes and about how this gives weight to their policy prescriptions. Appreciating what theory can and cannot contribute to our understanding of the past and to policy deliberations requires an understanding of how causal explanations are shaped by pragmatic choices. In IR's policy debates, just as in its historical and theoretical debates, we should attend closely to the pragmatics of causal explanation.

3 July 2015.

9482 words.

\section{Acknowledgements}

Earlier versions of this paper, under a different title, were presented at a workshop at the University of Reading and at the British International Studies Association annual conference in Dublin, both in 
June 2014. I am grateful to participants in both forums. Particular thanks are due to Hidemi Suganami, Patrick Jackson and two anonymous reviewers for thoughtful and constructive comments on earlier drafts.

\footnotetext{
${ }^{1}$ We might also intuit that the simpler explanation is more powerful in the sense that it can migrate more easily across cases. Although this may be valuable, it would not make it a better explanation
} of our immediate object of inquiry.

2 The meaning of 'pragmatic' here is analogous to its meaning in semiotics, where it is conventional to distinguish among syntax (the formal relationship between signs), semantics (the relationship between signs and what they signify) and pragmatics (the relationship between signs and their users). See van Fraassen (1980: 89-91).

${ }^{3}$ By 'interests' I mean explanatory interests, that is, what precisely we request an explanation of and how much detail we demand. Of course, we may have all kinds of reasons for pursuing particular explanatory interests: as Weber (2004) points out, this is one way in which value commitments enter into scholarly inquiry.

${ }^{4}$ This pragmatic aspect of causal explanation has been almost entirely ignored in recent discussions of philosophy of science in IR (see, for example, Patomäki \& Wight 2000), but is also explored in this volume by Jackson. For a broader discussion of what causal analysis in IR can learn from philosophy see Suganami, this volume.

${ }^{5}$ This is true irrespective of the epistemic criteria we employ for identifying causes. As Lewis (1993: 184) observes, '[w]hatever causation may be, there are still causal histories'.

${ }^{6}$ The Concert system is usually dated from 1815 to 1848 (Garrett 1976: 394) or 1853/4 (Schroeder 1986: 1), though some stress the continuities through 1914 (see Schulz 2007). It therefore includes, but extends beyond, the Congress system of 1814-1822 (see Jervis 1982: 362).

${ }^{7}$ In the work I examine here, the aim is to explain relative peace among the great powers. In what follows, all references to the system's 'peacefulness' carry this qualification.

${ }^{8}$ This kind of response may be found both in general discussions of the relationship between theory and history in IR (see Elman and Elman 2001) and in work on the Concert (see Goddard et al 2015). (I am grateful to a reviewer for bringing the latter to my attention.) However, Slantchev engages in significant historical work, while Schroeder explicitly engages with IR theory: this debate is therefore not (at least straightforwardly) a debate between theory and history.

${ }^{9} \mathrm{I}$ am grateful to a reviewer for posing the issue in these terms. 
${ }^{10}$ I am grateful to a reviewer for suggesting this form of words.

${ }^{11}$ On the role of general claims in causal explanation see Jackson, this volume.

12 I follow Suganami (2008) in rejecting a strong distinction between explanation and understanding.

${ }^{13}$ This formulation focuses on singular causal explanations. I further follow Lewis (1993: 192-3) in

believing that general explanations take an analogous form (see also Suganami 2008: 333).

${ }^{14}$ This analysis is not contingent on employing a counterfactual approach to causality. See Note 4, above. Lycan (2002: 414-6) discusses how pragmatic considerations enter into the evaluation of causal explanations even from a (scientific) realist perspective.

${ }^{15}$ I use van Fraassen because, unlike recent work on the philosophy of science in IR, he is centrally concerned with the pragmatic interests which motivate causal selection. Moreover, though van Fraassen is a committed empiricist, he is not vulnerable to the kinds of criticisms levelled at empiricism in IR by, inter alia, Patomäki and Wight (2000). I consider elsewhere the implications of debates between (scientific) realists and empiricists for causal inquiry in IR.

${ }^{16}$ I say 'highlights' because believing that explanation unavoidably involves a pragmatic component is not conditional on accepting van Fraassen's theory of explanations as answers to why-questions (see Achinstein 1993).

${ }^{17}$ For a recent treatment of the idea in IR see Grynaviski (2012).

${ }^{18}$ They therefore contend that van Fraassen is better understood as providing a theory of the pragmatics of causal explanation than as providing a pragmatic theory of explanation. Achinstein (1993: 330) makes a similar point, but with the opposite purpose: whereas Kitcher and Salmon imply that van Fraassen overstates the degree to which his approach is pragmatic, Achinstein argues that he doesn't go far enough.

${ }^{19}$ Kitcher and Salmon (1993: 323-5) seem to think that this entails an 'anything goes' account of causal explanation. It does not. If explanation is irreducibly pragmatic this neither removes the requirement for pragmatic adequacy nor removes the requirement that the causal net is scientifically identified.

${ }^{20}$ This was most explicit in the immediate aftermath of the Cold War (see Kupchan and Kupchan 1991; Rosecrance 1992). However, the Concert system has also been utilised as a point of comparison for conceptualising other periods of relative great power peace (see Cohrs 2003; Jervis 1985: 58; Garrett 1976). For a recent policy paper advocating a return to concert principles for managing great power conflict, see http://www.hsfk.de/fileadmin/downloads/PolicyPaper ATwentyFirstCenturyConcertofPowers.pdf (accessed 09 Dec, 2014). 
${ }^{21}$ These kinds of divisions are not only hard to draw convincingly: they also fail to align neatly. For example, Mitzen's approach is theoretical, yet much closer to Schroeder's than to Slantchev's (see Mitzen 2013: 27). Meanwhile, Schroeder is criticized by fellow historians both for understating (Gruner 1992) and overstating (Kraehe 1992) the system's complexity. Nor is Schroeder simply a prototypical constructivist: Schulz (2007) goes much further in this regard.

${ }^{22}$ Intriguingly, though, Jervis (1997) explores many of them.

${ }^{23}$ Schroeder (1996: 3-5) emphasizes that although the territorial settlement of 1815 was structurally similar to that of 1763 , the outcome was very different.

${ }^{24}$ Schroeder does not in fact talk of state 'preferences': this is rationalist language. See also Mitzen (2013: 32).

${ }^{25}$ This is not to say that it is epistemically adequate or that we should prefer it to other historical explanations. A comparison with a rival historical explanation would have to assess the adequacy of the reasoning and evidence that each provide for identifying certain factors as being causally important and also the pragmatic choices that each embodies.

${ }^{26}$ Jervis (1992: 724) recognizes that 'political science has not fully engaged' with the kind of systemic transformation described by Schroeder (1992) and others.

${ }^{27}$ Some might question whether the success of a model in explaining one particular case provides any grounds for confidence about its ability to explain a different case.

${ }^{28}$ Moreover, if Slantchev's position is that an adequate explanation takes actors' interests as given and asks how they play out, without accounting for how the actors arrived at those interests in the first place, then this strongly limits the utility of rationalist explanations as policy tools. 


\section{Bibliography}

Achinstein, Peter (1993) 'The Pragmatic Character of Explanation', in David-Hillel Ruben, ed., Explanation, 326-44, Oxford: Oxford University Press.

Buzan, Barry \& George Lawson (2013) 'The Global Transformation: The Nineteenth Century and the Making of Modern International Relations', International Studies Quarterly 57(3): 620-34.

Cohrs, Patrick O. (2003) 'The First "Real" Peace Settlements after the First World War: Britain, the United States and the Accords of London and Locarno, 1923-1925', Contemporary European History 12(1): 1-31.

Elman, Colin \& Miriam Fendius Elman, eds. (2001) Bridges and Boundaries: Historians, Political Scientists and the Study of International Relations, Cambridge: MIT Press.

Garrett, Stephen A. (1976) 'Nixonian Foreign Policy: A New Balance of Power, or a Revived Concert?' Polity 8(3): 389-421.

Goddard, Stacie E., George Lawson, Charles Maier, Matthew Rendall, Brian Vick, Mark Jarrett \& Jennifer Mitzen (2015) 'Roundtable 7-11 on the Congress of Vienna and Dialogue between IR Scholars and Historians' (H-Diplo/ISSF). http://issforum.org/roundtables/7-11-congress-ofvienna (accessed 04/05/15).

Gruner, Wolf D. (1992) 'Was there a Reformed Balance of Power System or Cooperative Great Power Hegemony', American Historical Review 97(3): 725-32.

Grynaviski, Eric (2013) 'Contrasts, Counterfactuals, and Causes', European Journal of International Relations 19(4): 823-46.

Ikenberry, G. John (2001) After Victory: Institutions, Strategic Restraint, and the Rebuilding of Order after Major Wars, Princeton, New Jersey: Princeton University Press.

Jervis, Robert (1982) 'Security Regimes', International Organization 36(2): 357-78.

Jervis, Robert (1985) 'From Balance to Concert: A Study of International Security Cooperation', World Politics 38(1): 58-79. 
Jervis, Robert (1992) 'A Political Science Perspective on the Balance of Power and the Concert', American Historical Review 97(3): 716-24.

Jervis, Robert (1997) System Effects: Complexity in Political and Social Life, Princeton, New Jersey: Princeton University Press.

Keene, Edward (2008) 'The English School and British Historians', Millennium: Journal of International Studies 37(2): 381-93.

Kitcher, Philip \& Wesley C. Salmon (1993) 'Van Fraassen on Explanation', in David-Hillel Ruben, ed., Explanation, 310-25, Oxford: Oxford University Press.

Kraehe, Enno E. (1992) ‘A Bipolar Balance of Power', American Historical Review 97(3), 707-15.

Kupchan, Charles A. (2012) How Enemies Become Friends: The Sources of Stable Peace, Princeton, New Jersey: Princeton University Press.

Kupchan, Charles A. and Clifford A. Kupchan (1991) 'Collective Security, and the Future of Europe', International Security 16(1): 114-61.

Kurki, Milja (2008) Causation in International Relations: Reclaiming Causal Analysis, Cambridge: Cambridge University Press.

Lawson, George (2010) 'The Eternal Divide? History and International Relations', European Journal of International Relations 18(2): 203-26.

Lewis, David (1993) 'Causal Explanation', in David-Hillel Ruben, ed., Explanation, 182-206, Oxford: Oxford University Press.

Lycan, William G. (2002) 'Explanation and Epistemology' in Paul K. Moser, ed., The Oxford Handbook of Epistemology, 408-33, Oxford: Oxford University Press.

Martin, Raymond (1982) 'Causes, Conditions, and Causal Importance', History and Theory 21(1): 53 74.

Mitzen, Jennifer (2013) Power in Concert: The Nineteenth-Century Origins of Global Governance, Chicago: University of Chicago Press. 
Patomäki, Heikki \& Colin Wight (2000) 'After Postpositivism? The Promises of Critical Realism', International Studies Quarterly 44(2): 213-37.

Rosecrance, Richard (1992) 'A New Concert of Powers', Foreign Affairs 71(2): 64-82.

Schroeder, Paul W. (1972) Austria, Great Britain, and the Crimean War: The Destruction of the European Concert, Ithaca: Cornell University Press.

Schroeder, Paul W. (1986) 'The $19^{\text {th }}$-Century International System: Changes in the Structure', World Politics 39(1): 1-26.

Schroeder, Paul W. (1989) 'The Nineteenth-Century System: Balance of Power or Political Equilibrium', Review of International Studies 15(2): 133-53.

Schroeder, Paul W. (1992a) 'Did the Vienna Settlement rest on a Balance of Power?' American Historical Review 97(3): 683-706.

Schroeder, Paul W. (1992b) ‘A Mild Rejoinder', American Historical Review 97(3): 733-5.

Schroeder, Paul W. (1996) The Transformation of European Politics 1763-1848, Oxford: Clarendon Press.

Schulz, Matthias (2007) ‘Did Norms Matter in Nineteenth-Century International Relations? Progress and Decline in the "Culture of Peace" Before World War I', in Holger Afflerbach \& David Stevenson, eds., An Improbable War? The Outbreak of World War I and European Political Culture before 1914, 43-60, New York: Berghahn Books.

Slantchev, Branislav L. (2005) 'Territory and Commitment: The Concert of Europe as Self-Enforcing Equilibrium', Security Studies 14(4): 565-606.

Suganami, Hidemi (2008) 'Narrative Explanations and International Relations: Back to Basics', Millennium: Journal of International Studies 37(2): 327-56.

Van Fraassen, Bas (1980) The Scientific Image, Oxford: Clarendon.

Weber, Max (2004) The "Objectivity" of Knowledge in Social Science and Social Policy', in Sam Whimster, ed., The Essential Weber: A Reader, 359-404, London: Routledge. 
Woodward, James (1993) 'A Theory of Singular Causal Explanation', in David-Hillel Ruben, ed., Explanation, 246-74, Oxford: Oxford University Press. 